\title{
Negative partisanship is not more prevalent than positive partisanship
}

\author{
Amber Hye-Yon Lee ${ }^{1}$, Yphtach Lelkes ${ }^{2}$, Carlee B. Hawkins ${ }^{3}$, and Alexander G. \\ Theodoridis ${ }^{4}$
}

\author{
${ }^{1}$ Consortium on Electoral Democracy, Ryerson University, Toronto, Canada \\ ${ }^{2}$ Annenberg School for Communication, University of Pennsylvania, Philadelphia, USA * \\ ${ }^{3}$ Department of Psychology, Southern Illinois University Edwardsville, Edwardsville, USA \\ ${ }^{4}$ Department of Political Science, University of Massachusetts Amherst, Amherst, USA
}

\begin{abstract}
The dominant narrative among scholars and political pundits characterizes American partisanship as overwhelmingly negative - portraying citizens as more repelled by the opposing party than attached to their own party. To assess the valence of partisan identity, we use novel measures, several new and existing nationally representative surveys, and behavioral outcomes obtained from two experiments. Our findings consistently depart from the negative partisanship narrative. For the majority of Americans, partisanship is either equally positive and negative or more positive than negative. Only partisan leaners stand out as negative partisans. We pair these observational findings with experimental data that differentiate between positive group behavior and negative group behavior in the partisan context. We find that the behavioral manifestations of party identity similarly include both positive and negative biases in balance, reinforcing our conclusion that descriptions of partisanship as primarily negative are exaggerated.
\end{abstract}

\begin{abstract}
What is corroding American politics is, specifically, negative partisanship: Although most liberals feel conflicted about the Democratic Party, they really hate the Republican Party. And even though most conservatives feel conflicted about the Republican Party, they really hate the Democratic Party. America's political divisions are driven by hatred of an out-group rather than love of the in-group.

- Yascha Mounk, The Atlantic
\end{abstract}

According to contemporary portrayals in the scholarly literature and the press, American political parties "hang together mainly out of sheer hatred of the other team, rather than a shared sense of purpose" ${ }^{1}$. In this view, the current state of partisanship is more negative than positive, and negativity is the primary driver of voter behavior ${ }^{2 ; 3 ; 4 ; 5 ; 6 ; 7 ; 8 ; ; ; 10 ; 11 ; 12}$. Negative partisanship has been defined in terms of affect as well as an identity. Negative partisanship as affect is centered around the idea that (negative) animosity toward the other party is greater than (positive) in-party attachments ${ }^{2}$. Negative partisanship as affect is based on the notion that people support a political party because of their opposition to the other party; it is thus a negational identity. Researchers have argued that out-group dislike (relative to in-group favoritism) and negational identity drive political participation ${ }^{13}$ (but see ref. ${ }^{14}$ ), split-ticket voting ${ }^{3}$, and opposition to bipartisanship ${ }^{14}$.

It is true that partisan animosity has increased in recent decades. Scholarship on mass polarization has demonstrated the widening gap between positive affect toward one's preferred party and negative affect toward the opposing party. This gap is primarily driven by increases in negative evaluations of the other side, while evaluations of one's own side remain largely stable ${ }^{15}$.

However, there are several reasons to be skeptical of the claim that negative partisanship dominates over positive partisanship in American politics. First, negative partisanship seemingly contradicts decades of social psychological research on social identity theory ${ }^{16}$, which holds that in-group favoritism is the result of in-group identification. In this view, out-group animosity is viewed not as the cause of in-group identity and favoritism, but as the outcome of in-group favoritism ${ }^{17 ; 18}$. Recent work on political homophily is in line with these conclusions. For example, experimental and observational studies show that individuals select dating partners who share their political beliefs ${ }^{19}$. This in-group favoritism may result in discrimination against the out-group (i.e., not dating people with dissimilar political beliefs), but only insofar as the positivity afforded in-groups is not extended to the out-group (see also ref. ${ }^{20}$ ). The negative partisanship narrative would predict that individuals choose dating partners with similar political beliefs because they are hostile toward those with dissimilar beliefs, but this interpretation represents a causal path that is contradicted by social identity theory and traditional views of political partisanship. In other

\footnotetext{
*Corresponding author: Yphtach Lelkes (ylelkes@upenn.edu; ORCID linked to account on Manuscript Tracking System)
} 
words, negative partisanship presents a departure from traditional portrayals of partisanship as an object of affinity, wherein parties are held together by "a shared sense of purpose." Second, recent studies in political science suggest that negative partisanship is not always a stronger predictor of political behavior than positive partisanship ${ }^{14 ; 21 ; 22}$. Additionally, citizens punish politicians that use vitriolic rhetoric ${ }^{23}$. Finally, some literature suggests that dislike of the other side is not driven by sincere distaste for the out-group and its policies but by misperceptions ${ }^{24}$.

Negative partisan identity and positive partisan identity are two distinct constructs, each with different political consequences ${ }^{14 ; 25}$. Nevertheless, it is still unclear which type of partisanship is more prevalent among American partisans. The typical study assesses the importance of negative and positive partisanship by including both measures in a single regression model to predict a political outcome ${ }^{2 ; 14 ; 25}$. However, this approach is likely to lead to model misspecification and produce biased estimates if, as Tajfel ${ }^{26}$ points out, negative identities emanate from positive identities ${ }^{27}$. Additionally, since neither negative nor positive partisanship is manipulated in these studies, their relationship with a purported outcome may be spurious.

In this study, we take a more straightforward approach than the typical model. Rather than trying to compare the dominance of negative versus positive partisanship by estimating their effect on some political outcome, we use an approach that is more intuitive and less prone to errors. We estimate their relative prevalence using more refined methods and measures that can separate positive in-group attitudes and behavior from negative out-group attitudes and behavior.

Because identity and affect are mutually exclusive constructs ${ }^{28 ; 29}$ and have potentially disparate outcomes ${ }^{13}$, we include measures of both aspects of negative partisanship. Further, because partisan animosity depends on whether the measures focus on elites versus the mass public ${ }^{30}$, we use measures that capture attitudes towards both. Across an array of measures and approaches, we consistently find no evidence that negative partisanship in terms of affect as well as identity are predominantly negative. Regardless of whether we operationalize negative and positive partisanship based on feeling thermometer difference scores, measures of negational-to-affirmational identity, or separate positive and negative partisan identity measures, we find no evidence that negative partisanship is stronger than positive partisanship. For those who identify themselves with a political party, such as strong and weak partisans, their partisan identity is based on both positive in-party attachments and negative out-party animosity, with the former often being primary to the latter. On the other hand, partisan leaners, those who initially identify as Independents but then acknowledge a preference for a political party, tend to be negative partisans.

We also provide experimental evidence from two pre-registered (https: / / osf . io/ez jsf) behavioral experiments. Our experiments use a game paradigm called the intergroup prisoners' dilemma-maximizing difference (IPD-MD) game, which is well suited to differentiating positive and negative partisan behavior and assessing which is more common among ordinary voters. Participants are asked to choose between favoring in-group members (i.e., positive in-group behavior) and disfavoring out-group members (i.e., negative out-group behavior). Using two sets of experiments, we examine the valence of partisan behavior, comparing between in-group favoritism and active out-group animosity (Experiment 1) and between in-group favoritism and passive out-group animosity (Experiment 2). In both experiments, negative out-party animosity does not exceed positive in-party favoritism for most people, which challenges arguments about the predominance of negative partisanship.

The nature of partisanship and partisan bias has important implications for democratic politics. If partisan divisions are predominantly driven by out-party animosity, it indicates that our political climate is far more toxic than if in-party affection is the primary force. To the extent that partisans are motivated by a desire to hurt their political opponents more than to support those of the same party, it poses a threat to fundamental democratic principles, such as tolerance of different viewpoints and fair and honest elections between competing group interests ${ }^{7}$. Additionally, negative partisanship calls into question a central tenet of democracy and representation: we have long assumed that people support policies and policymakers that represent their material or group interests rather than policies and policymakers that hurt their political opponents. Our findings support this classic understanding of political support and call into question more recent claims that partisanship is based on out-group animosity.

\section{Results}

To investigate the prevalence of positive and negative partisanship in the American population, we draw on four different data sources, with each using different operationalizations of partisan identity and attachments. Data are from (1) the American National Election Studies (ANES), (2) the Cooperative Congressional Election Study (CCES), (3) an online non-probability sample collected by Bankert ${ }^{14}$, and (4) online behavioral experiments.

\section{Positive and negative partisan identity based on difference scores from party feeling thermometers}

Our first measure comes from the American National Election Studies data from 1978 to 2016. We use feeling thermometer ratings of political parties and construct the measure of negative partisanship following the definition from previous work ${ }^{2}$. Although this measure is often used to refer to negative partisanship as a negational identity ${ }^{25}$, it most clearly measures partisan affect. 
Figure 1 plots the difference between in-party and out-party feeling thermometer ratings. Scores above 0 indicate that one's negative feelings toward the opposing party are greater than one's positive feelings toward their party. In contrast, scores below 0 suggest that one's positive in-party affect is greater than one's negative out-party affect. In other words, when this difference score is greater than 0 , it means that partisans dislike the other party more than they like their party so that they can be classified as negative partisans. On the other hand, those with scores below 0 are classified as positive partisans because they like their party more than they dislike the other party.

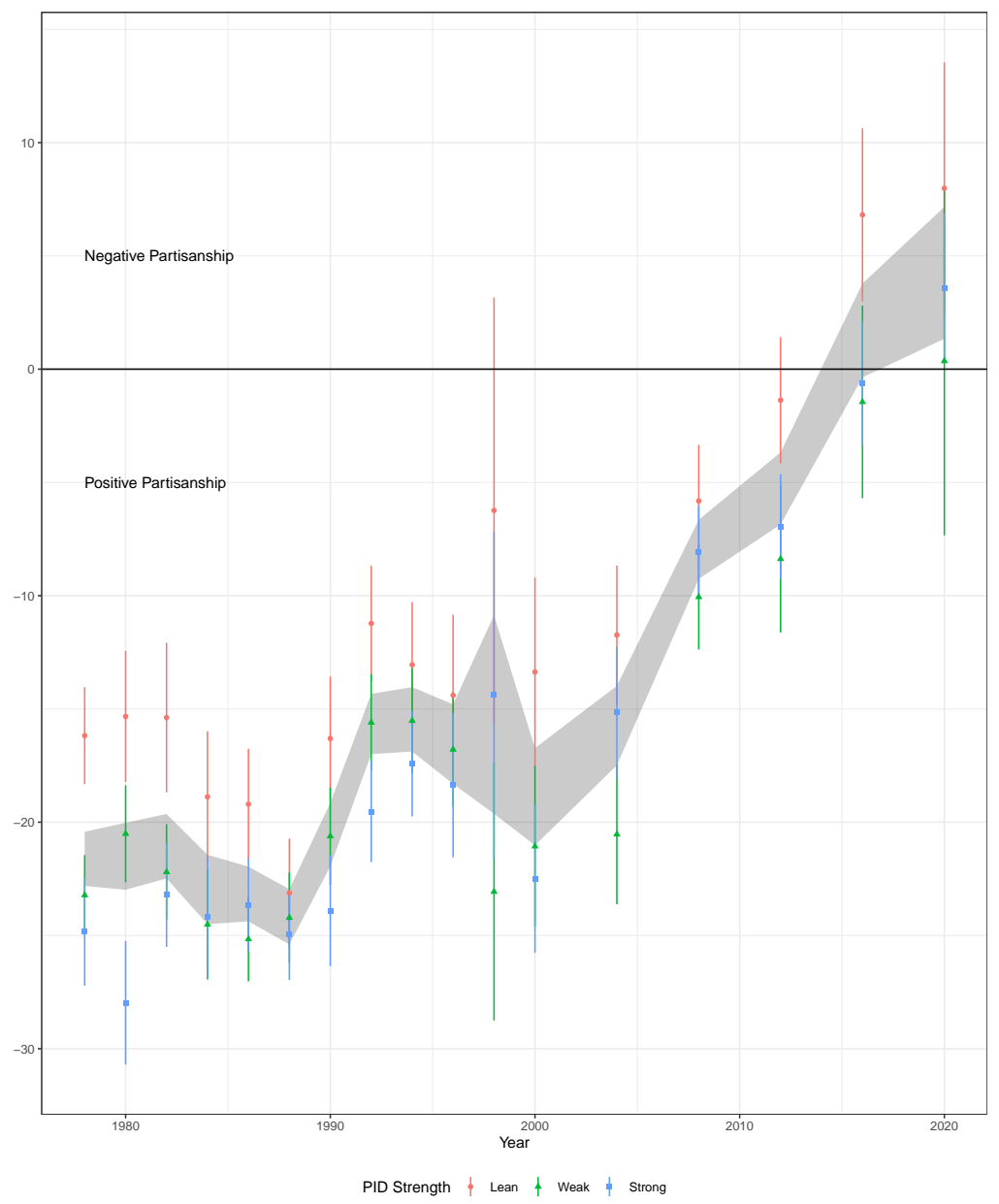

Figure 1. Negative and positive partisanship based on party feeling thermometer difference scores. 1978-2020 ANES.

In the figure, we can see the rise of negative partisanship over the past 30 years. However, even in 2016, which was viewed by many as a high point for negative partisanship ${ }^{1}$, this measure's average score hovered around zero $(M=1.71, S E=0.87$, $P=.05$, Bayes Factor $B F=.24$ ), meaning that the extent of negative partisanship is on par with positive partisanship. We also find substantial heterogeneity by strength and type of party identification. For strong partisans and weak partisans, i.e., those who identify with a party, their partisan identity involved a balanced mix of both positive in-party and negative out-party attitudes. On the other hand, leaners tended to exhibit stronger out-party negativity than in-party attachment.

Negative partisanship outpaced positive partisanship for the first time in $2020(M=4.25, S E=1.17, P<.001, B F=37.61$. This was primarily driven by partisan leaners $(M=7.98, S E=2.24, P<.001, B F=36.28)$. Weak partisans' scores $(M=0.36$, $S E=2.84, P=.90, B F=.13$ ) were not significantly different from zero. While the score for strong partisans was significantly greater than zero, the Bayes Factor coefficient was quite small $(M=3.58, S E=1.46, P=.02, B F=1.59)$

\section{Positive and negative partisan identity based on a negational-to-affirmational identity scale}

One of the limitations of the feeling thermometers is that they do not directly measure whether people form a political identity based on positive considerations (e.g., positive attitudes toward a party), negative considerations (e.g., negative attitudes toward a party), or both. To assess the extent to which one's partisanship is grounded in positive identification with the in-party or negative disidentification with the out-party, we used a negational-to-affirmational identity measure adapted from prior 
research $^{31}$ and fielded the item in the 2016 Cooperative Congressional Election Study (CCES) Survey $(n=1,611)$. This measure asks whether respondents' party affiliation is based more on belonging to their own party (affirmational), more on not belonging to the other party (negational), or equally on both.

Note that this survey was conducted the 2016 presidential election, a political moment discussed as a high point in negative partisanship. Despite this period, we find little evidence to support the prevalence of negative partisanship. As shown in Panel A in Figure 2, only $18 \%$ of partisan respondents said their party identity was negational or based more on (negative) out-party disidentification, while 57\% reported having affirmational party identity based on (positive) in-party identification. For $25 \%$ of respondents, their partisanship was defined equally by identifying with their own party and not identifying with the other party. The overall mean score of negational-to-affirmational identity was $.86\left(S E=0.05, B F=2.97 \times 10^{50}\right)$ on a scale of -3 (very negational) to 3 (very affirmational). Based on this measure, partisanship can be said to be generally more positive than negative.
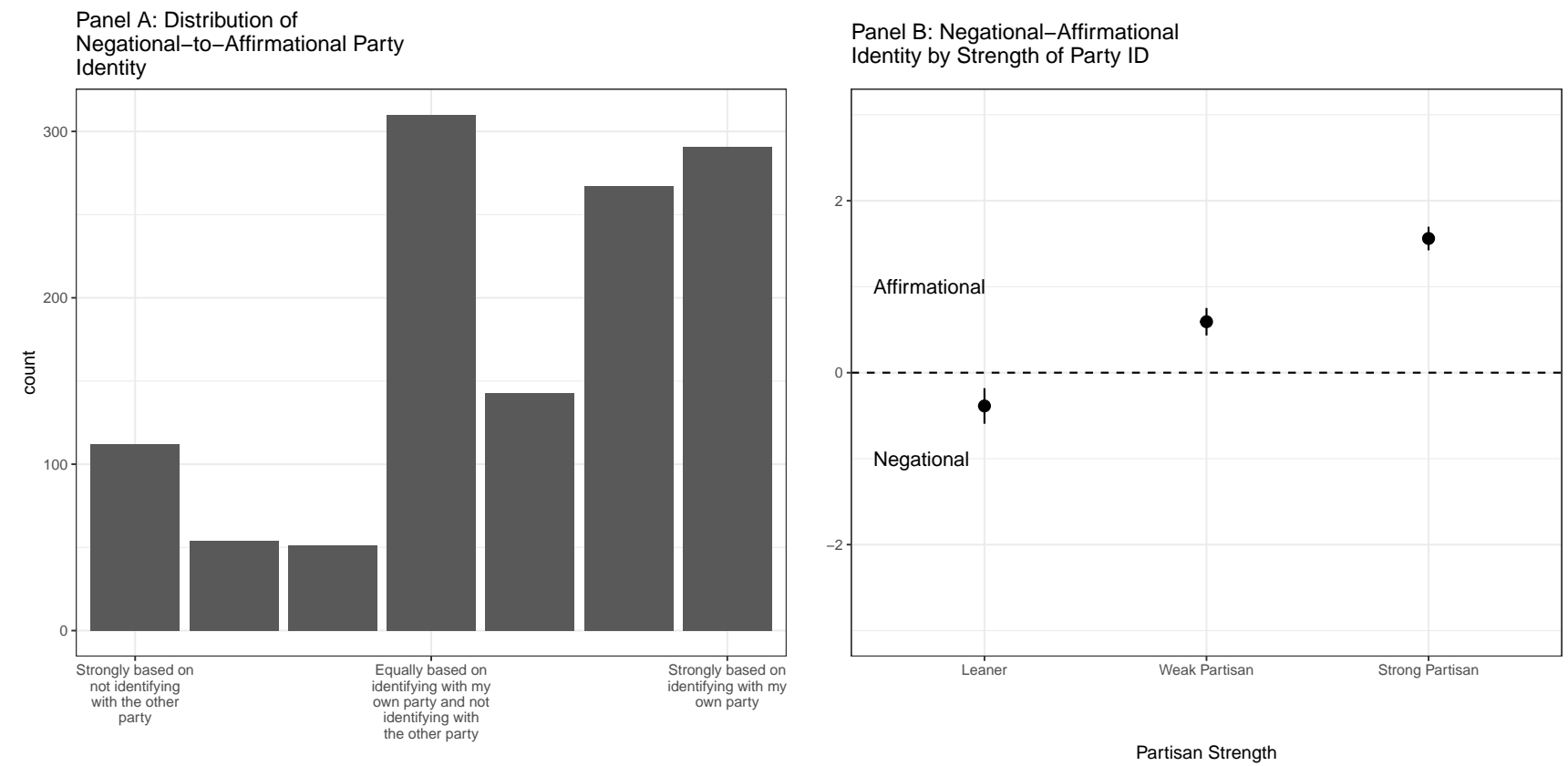

Figure 2. Distribution of explicit negational-to-affirmational party identity (Panel A). Mean score by party identity strength (Panel B). 2016 CCES.

Moreover, responses to the negational-to-affirmational party identity scale varied by identity strength. Panel B in Figure 2 shows how negative or positive party identity is, on a scale ranging from -3 to 3 , among leaners, weak partisans, and strong partisans. Strong partisans and weak partisans were more likely to identify with their party for affirmational reasons, while the only group whose identity tended to be more based on negational grounds was leaners, whose average score was slightly below zero on the scale.

Additionally, our analysis suggests that party feeling thermometer measures-or at least out-party feeling thermometermay not be accurate indicators of negative and positive partisanship as an identity. In Figure 3, we plot the average in-party and out-party feeling thermometer rating across the negational-to-affirmational partisan identity scale. Our identity scale was strongly and linearly related to in-party ratings. For those who identify as positive partisans, the mean feeling thermometer ratings for the in-party was around 75, while those who identify as negative partisans rated their party at about 60 on average. However, the negational-to-affirmational partisan identity was not related to feelings towards the out-party.

\section{Positive and negative partisan identity based on the positive and negative partisan identity scale}

Next, we use a sample of data collected by Bankert ${ }^{14}$, who developed scales that examine positive and negative partisan identity, separately. Bankert used positive and negative versions of a commonly used partisan identity scale ${ }^{32}$. For instance, a positive identity item was worded as, "When I talk about this party, I say 'we' instead of 'them"' and a negative identity item was worded as, "When people criticize this party, it makes me feel good." The data were collected in November 2016 from an online non-probability panel that was broadly representative of the US population in terms of age, gender, race and census region $(n=778)$. 


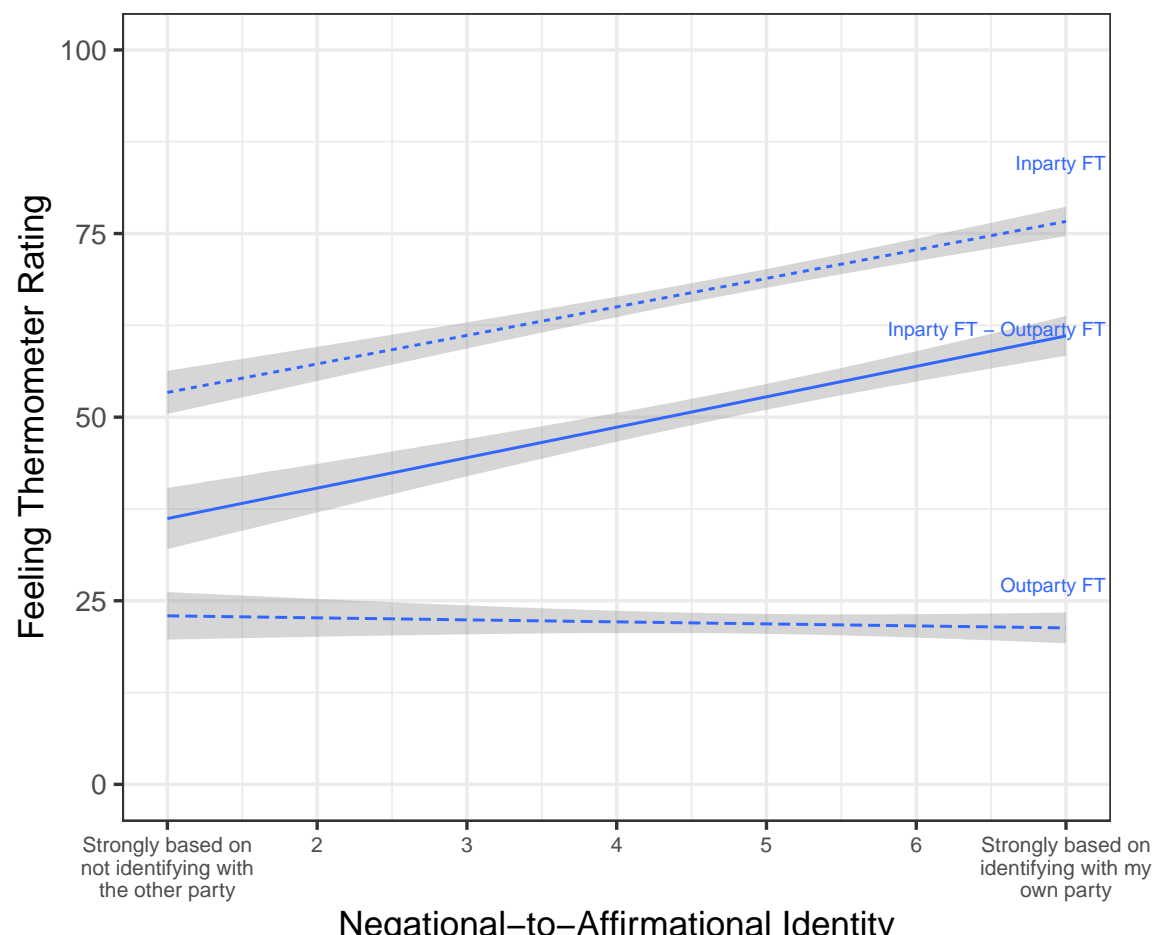

Figure 3. Fitted values from bivariate OLS models predicting in-party, out-party, and in-party-out-party feeling thermometers from the negational-to-affirmational identity measure. 2016 CCES.

The mean score for positive partisanship was 0.51 on a $0-1$ scale $(S E=0.01)$, which was significantly higher than the mean score for negative partisanship $(M=0.45, S E=0.01, t=4.55, P<.001, B F=1476) .51$ percent of respondents had higher positive partisanship scores than negative partisanship scores, 35 percent had higher negative partisanship scores than positive partisanship scores, and 15 percent were equally positive as they were negative. The distribution of the difference score (positive party identity-negative party identity) is displayed in Panel A, Figure 4.
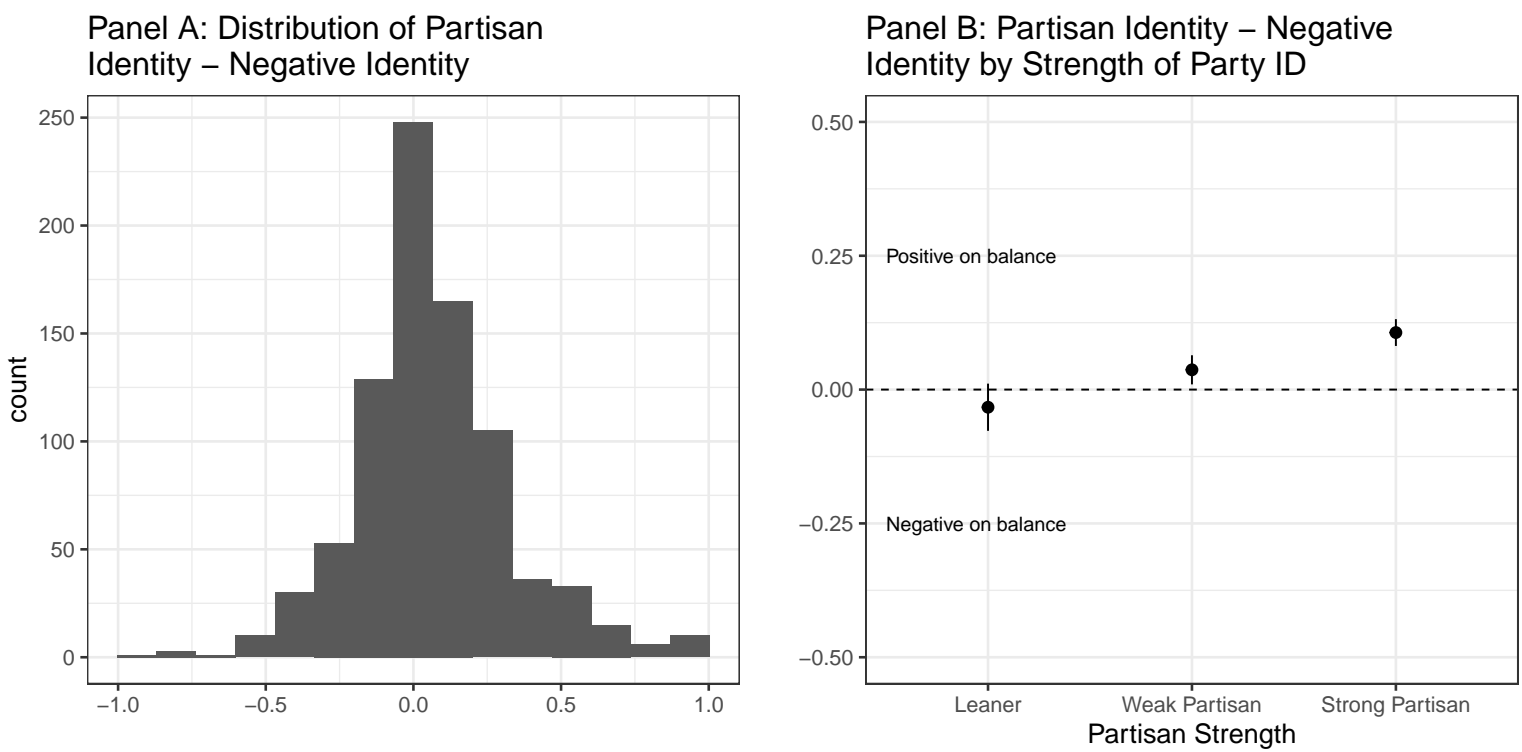

Figure 4. Positive and negative party identity (Panel A). Mean score by party identity strength (Panel B) 2016 SSI. 
As with the other survey measures, strong partisans were, on balance, positive partisans, in that their positive partisan identity scores were higher than their negative partisan identity scores. On the other hand, leaners tended to be negative partisans - their negative partisan identity scores were higher than the positive partisan identity scores. Additionally, while Democrats and Republicans were equivalent on the negative partisan identity scale, $\left(D_{\text {Kolmogorov }- \text { Smirnov }}=.06, P=.47\right)$, Republicans were far lower on the positive partisan identity scale than Democrats $\left(D_{\text {Kolmogorov }- \text { Smirnov }}=.12, P<.01\right.$; see Appendix A.)

Finally, consistent with the negational-to-affirmational results, out-party feeling thermometer scores were only weakly correlated with negative and positive partisanship (see Figure 5). The correlation of the negative partisanship measure with out-party feeling thermometers was -.07 (Left Panel, long dashed line), and its correlation with in-party feeling thermometers was .23 (Left Panel, short dashed line). The correlation between the positive partisanship measure and feelings towards the out-party was .07 (Right Panel, long dashed line), and between the positive partisanship measure and feelings toward the in-party, the correlation was .49 (Right Panel, short dashed line).
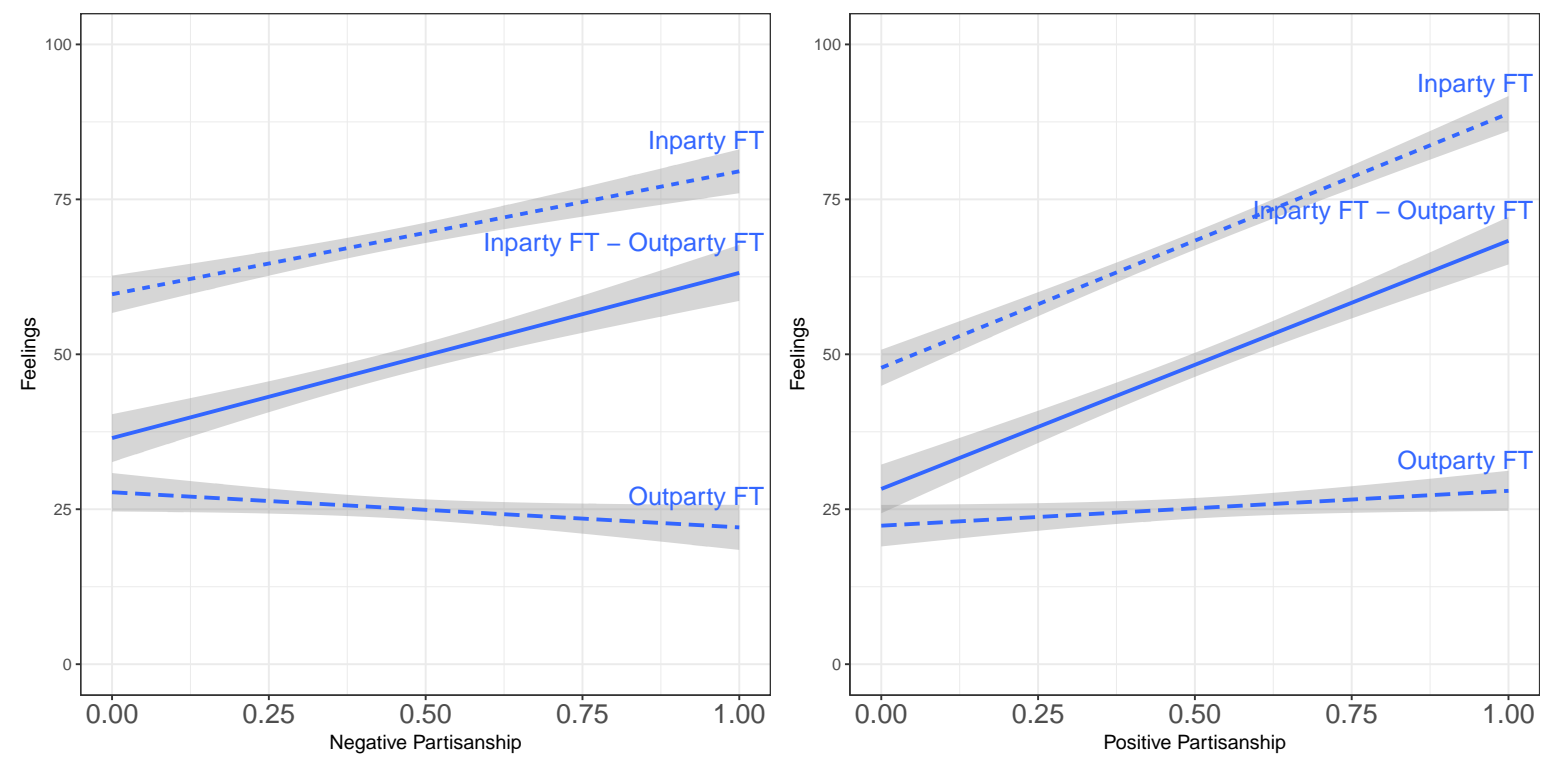

Figure 5. Fitted values from bivariate OLS models predicting in-party, out-party, and in-party-out-party feeling thermometers from the negative partisan identity (left) and positive partisan identity (right) measures. 2016 SSI.

In sum, across different samples and different measures and operationalization, negative partisans do not outnumber positive partisans. The only people that identify as negative partisans are those who lean towards a party. Furthermore, the primary piece of evidence for negative partisanship (the decline in out-party feelings over time) is only weakly correlated with more direct measures of negative and positive partisanship.

\section{Measuring positive and negative partisan behavior using behavioral experiments}

We now turn to an experimental design. Survey self-reports are often susceptible to social desirability bias or expressive rhetoric, which are obstacles to measuring sincere responses. For partisan identity, it is unclear which direction these biases would operate. However, they are concerning for our study if one is unwilling to admit the negative nature of their party identity or exaggerates affinity for their party or animosity toward the out-party. To avoid such potential response bias, researchers have looked for ways besides a survey to get a more accurate measure of political preferences ${ }^{33}$. In particular, behavioral economic games have become an increasingly popular tool to measure inter-party bias through observing people's behavior in the game ${ }^{34 ; 35 ; 36}$. By offering direct incentives such as financial rewards, these games can better garner truthful responses relative to survey-based methods.

In this study, we conduct a novel experiment based on the intergroup prisoner's dilemma-maximizing difference (IPD-MD) game $^{37 ; 38}$. This game is useful for distinguishing between behavior driven by positive group identity (i.e., in-group favoritism) and behavior driven by negative group identity (i.e., out-group animosity).

Previous IPD-MD experiments have mostly relied on convenience samples of college students and employed the minimal group paradigm $^{37 ; 39}$. There are, however, a few exceptions; for example, one study used real groups, such as political parties in Germany ${ }^{38}$. However, the political climate in Germany is quite different from the US in terms of the degree of political 
polarization and the number of parties (two-party dominant vs. multi-party systems), which makes the generalizability of findings uncertain to the US context. More recently, an experiment based on a variant of the IPD-MD game was conducted on an American sample of Mechanical Turk workers ${ }^{40}$. There, all participants were led to believe they were playing with a team of co-partisans against a team of opposing partisans. Since the partisan makeup of teams was not experimentally manipulated in their study, it is difficult to disentangle the role of partisanship from the effect of simply being on a different team.

In our IPD-MD game, there are two groups, Group A and Group B, and participants ("players") are placed into a group with two other people. They each receive an endowment of 10 tokens. Participants are shown the personal profiles of all six players in the game, including age, gender, movie preferences, and party affiliation, and then asked to decide how to allocate their tokens. We include non-political information in addition to partisanship to increase the ecological validity of the findings and minimize the reliance on party cues. Every player has the same set of choices: contribute to benefit their own group, contribute to harm the other group, or not engage in group behavior. We focus on the first two choices and compare which motivation-positive in-group favoritism or negative out-group animosity-is a more dominant force behind group behavior. If the latter is stronger than the former in a partisan group context, it is fair to say that negative partisanship predominates. The procedure is illustrated in Figure 6.

The key feature of our experiment is the manipulation of partisan composition between the groups. One's teammates (those in the same group) always share the same partisan identity whenever party information is available. What we experimentally vary is the partisanship of one's opponents (those in the opposing group). Participants are thus randomly assigned to play against an opposing group comprised of out-partisans (Different Party), an opposing group comprised of co-partisans (Same Party), or with no partisanship information (No Party Cue Condition). Other pieces of information than party affiliation are randomized so as not to confound the results with party treatment.

We compare these three party conditions to see whether individuals behave differently when the game is a match between two political rivals - when one's teammates are co-partisans while one's opponents are out-partisans-as opposed to when there is no clear out-party-when all players, both teammates and opponents, are co-partisans, or when there is no information about anyone's partisanship. Group identity is most likely to be activated in the presence of a clear out-group ${ }^{41}$. With this design, we can assess to what extent inter-party bias involves positive and negative group behaviors, specifically determining the nature of bias based on partisanship apart from that based on minimal group membership.

We use the original version of the IPD-MD game in Experiment $1^{37}$ and a modified version in Experiment $2^{38}$. They are both designed to distinguish negative out-group behavior from positive in-group behavior to assess which is stronger, but they differ in terms of which form of negative out-group behavior they measure. Experiment 1 focuses on active out-group animosity, that is, actively trying to harm the out-group, and Experiment 2 focuses on a more passive form, that is, indirectly trying to disadvantage the out-group, such as refusing to help.

Experiment 1 Each player is offered three choices: they can keep the tokens, or they can contribute some of them to their group, either to a Group Fund or to a Competitive Fund. They can split the tokens in any way they like. Contributing to either of the funds is costly to the individual but beneficial to the group. Both contributions to the Group Fund and Competitive Fund benefit one's fellow players in the same group. However, the Competitive Fund hurts one's opponents by reducing the payoffs of each player in the other group, whereas the Group Fund does not affect the opponents. Therefore, those who want to make group contributions can choose between the Group Fund that simply benefits teammates and the Competitive Fund that benefits teammates while simultaneously hurting opponents. Note that rewarding teammates can be achieved by contributing to either fund. However, contributing specifically to the Competitive Fund suggests that one wishes to purposely harm those in the opposing group, which indicates active out-group animosity (See Figure 6a).

To determine whether negative partisanship is dominant, we took the difference between contributions to the Group Fund and Competitive Fund for each participant. Values less than zero indicate that participants contributed more to the Competitive Fund than the Group Fund. For them, we can say that their behavior was motivated by a desire to hurt those in the other group more than simply wanting to help those in the same group.

If partisanship is primarily negative, individuals should give more to the Competitive Fund in the presence of out-partisans. So, when we compare the contribution rates to the two funds across conditions, we should find that people in the different-party condition are more likely to choose the Competitive Fund over the Group Fund than those in the no-party-cue and same-party conditions, since in such two conditions, there is no information explicitly cueing people to think in terms of in-party and out-party. Even in the same-party condition, partisan information would not be particularly salient because there are no partisan rivals in the game and other non-political pieces of information are present. The negative partisanship view would expect negative out-group behavior to exceed positive in-group behavior when partisan identity is activated. In this view, the Group Fund minus Competitive Fund contributions should be particularly negative in the different-party condition compared to other two conditions.

The top panel of Figure 7 shows the average difference in contributions to the two funds (calculated as the Group Fund contributions subtracted from the Competitive Fund contributions) for each condition. Absent out-partisans, participants 


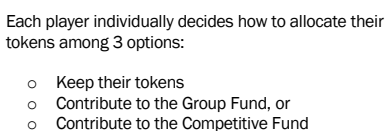

(3) For each token $\mathrm{P} 1$ contributes to the Competitive Fund: It increases the payoffs to $\mathrm{P} 1$ and each of their teammates by 1 token and decreases the payoffs to each player in Team B by 1 teammates by 1 token.
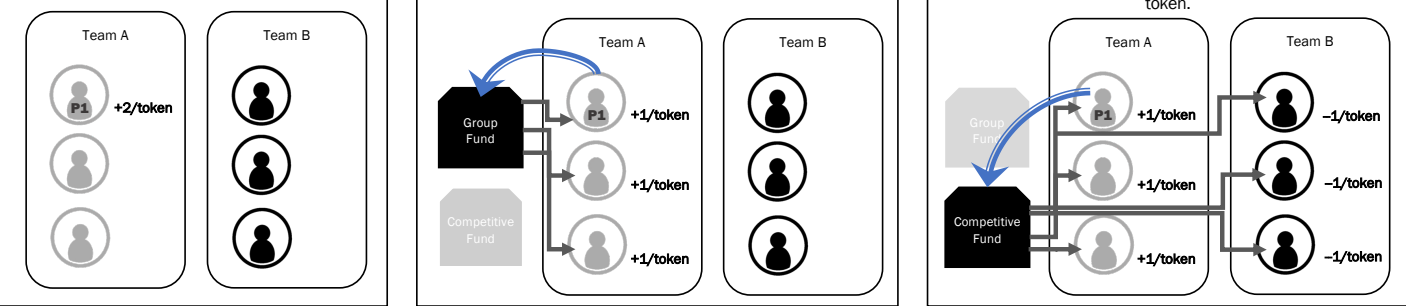

Contribution to the Competitive Fund > Contribution to the Group Fund One wants to hurt the opposing team
Negative partisan behavior (active)

(a) Experiment 1 Procedure: Active Animosity Experiment
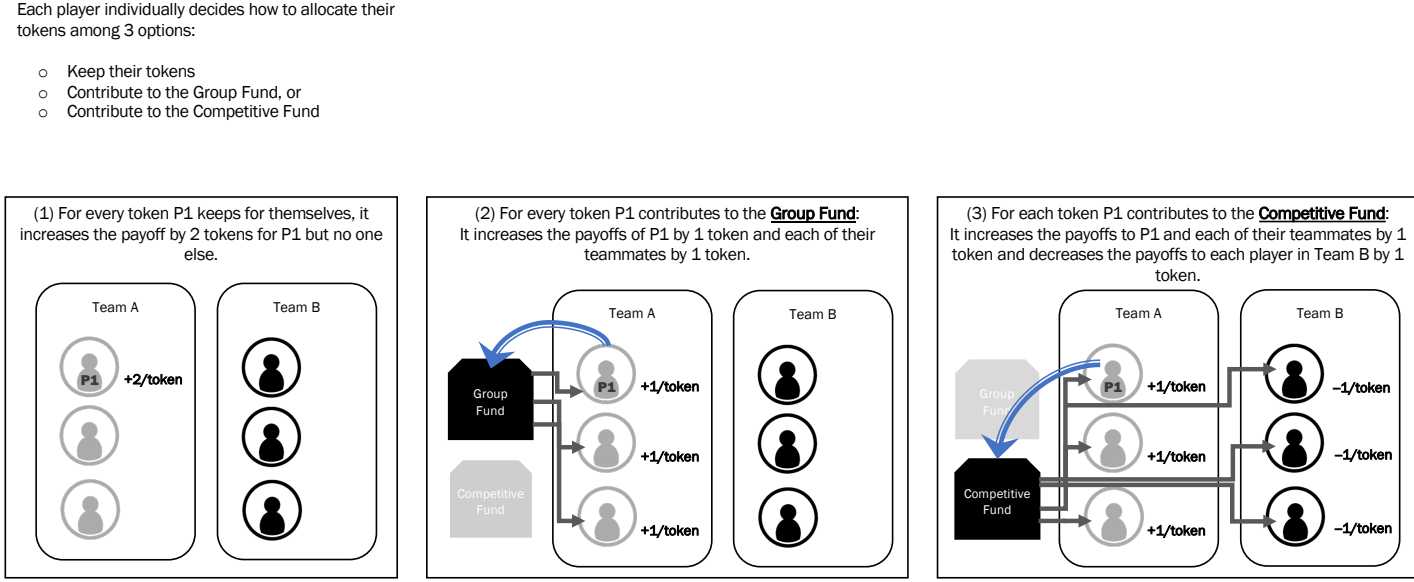

Contribution to the Competitive Fund > Contribution to the Group Fund One wants to hurt the opposing team

(b) Experiment 2 Procedure: Passive Animosity Experiment

Figure 6. Schema and expectations for active (a) and passive (b) animosity experiments.

generally contributed more to the Group Fund, which suggests the influence of positive in-group behavior, or favoritism toward their fellow players. In the different-party condition, however, the presence of out-partisans made way for increased contributions to the Competitive Fund. But even then, the contribution rates to the Competitive Fund and Group Fund were about the same, producing a difference value between the two funds very close to zero $\left(M_{\text {Group-Competitive }}=-0.04,95 \%\right.$ CI [-0.72 0.64], $P=.90, B F=.06$ ). If behavior based on partisan identity is predominantly negative, we would have seen a definite negative value, which is not the case here.

To compare the means of the contribution difference across conditions, we analyzed the data using a linear mixed-effects 
regression model with random intercepts for each participant. We also used contrasts to test for differences between the different-party condition and the two other conditions. The results are shown in tables in Appendix B. The analysis shows that the different-party condition was not statistically different from the same-party condition $(b=.63, S E=0.49, P=.20$, $B F=0.07)$ and the no-party-cue condition $(b=.88, S E=0.49, P=.07, B F=.16)$. When cued by partisanship and an inter-party context, people's behavior toward their opponents did not appear to be more negative than when party membership was irrelevant. In other words, we find no evidence that people were focused on hurting out-partisans in the opposing group, any more than wanting to benefit their own group of co-partisans, which does not fit with the negative partisanship view. We found little evidence that partisans were more motivated by negative out-group animosity than positive in-group favoritism. If anything, they engaged in both positive and negative behavior to a similar extent.

Moreover, we find no significant interaction between treatment condition and strength of party identity $(F=.60, P=.55)$. This suggests that the valence of partisan behavior did not significantly differ between strong partisans and weak or leaning partisans. Nevertheless, the values of the contribution difference were slightly different between two partisan subgroups, which is worth noting. As shown in the bottom panel of Figure 7, weak partisans and leaners in the different-party condition on average contributed more, although not significantly, to the Competitive Fund than the Group Fund $\left(M_{\text {Group }}-\right.$ Competitive $=-0.61$, 95\% CI [-1.76, 0.55], $P=.30, B F=0.16)$, whereas strong partisans on average contributed more, although not significantly, to the Group Fund than the Competitive Fund $\left(M_{\text {Group-Competitive }}=0.26,95 \%\right.$ CI $\left.[-0.58,1.11], P=.54, B F=0.08\right)$. The tendency to punish out-partisan opponents was somewhat stronger among weak and leaning partisans than among strong partisans, but for both subgroups, negative out-group behavior hardly exceeded positive in-group behavior. The difference between the contribution rates to the Group and Competitive Funds was not significantly different from zero for both partisan subgroups.

Experiment 2 In Experiment 2, we focus on a different form of out-group animosity: passive harm. Rather than actively causing harm to the out-group, people may engage in negative out-group behavior more indirectly ${ }^{42}$. For instance, people may attempt to disadvantage out-group members by withholding benefits or limiting resources to them ${ }^{43}$. Some argue that group discrimination in contemporary society increasingly takes the form of selectively helping people based on whether or not the recipients share the same identity ${ }^{18}$.

To examine the interplay between in-group favoritism and passive out-group animosity, we use a variant of the IPD-MD game $^{38}$, in which participants are allowed the choice of not helping players in the opposing group (instead of directly hurting them as in Experiment 1). Experiment 2 follows the same procedure as in Experiment 1, but group contribution returns slightly different payoffs to the players here. Here, participants are also randomly assigned to one of three conditions, which differ only by the partisanship of opponent players: whether they are out-partisans (Different Party), co-partisans (Same Party), or no-party information (No Party Cue). After seeing player profiles, participants make decisions about how to allocate their tokens: how many tokens they want to keep and how many tokens to contribute to their group, which could go to either the Exclusive Fund or the Common Fund.

The Exclusive Fund serves the same role as the Group Fund in Experiment 1, in that the contribution benefits one's own group but has no effect on the opposing group. However, contribution to the Common Fund benefits everyone in the game - those in the same group, as well as the opposing group. The choice of group contribution now comes down to rewarding teammates only (Exclusive Fund) or rewarding both teammates and opponents (Common Fund). Participants can help their teammates by contributing to either fund, but specifically choosing the Exclusive Fund over the Common Fund can be viewed as behavior intended to withhold benefits from opponents, indicating passive out-group animosity (See Figure 6b).

The negative partisanship view would predict that the presence of out-partisans increases contribution to the Exclusive Fund over the Common Fund. In other words, when opponents are out-partisans, negative partisanship is expected to lead people to make benefits only exclusive to their own group of co-partisans and not share them with out-partisans. To test this, we subtracted individual contributions to the Exclusive Fund from the Common Fund. When this quantity is negative, it means that one is motivated more by negative out-group animosity (not wanting to advantage the out-group) than positive in-group favoritism (wanting to help one's own group). If negative partisanship dominates, we should see this quantity being clearly negative in the different-party condition (when opponents are out-partisans) than in the same-party or no-party-cue conditions in which partisan motivations are unlikely to be activated.

The top panel in Figure 8 plots the difference in contributions to the two funds, the Common Fund contribution subtracted from the Exclusive Fund contribution, for each condition. In all conditions, participants on average contributed more to the Exclusive Fund than to the Common Fund. In other words, regardless of whether opponent players were out-partisans, co-partisans, or those with unknown party affiliation, participants were likely to show passive out-group animosity across the board toward those arbitrarily assigned to be opponents in the game.

What is important is that this general tendency of passive out-group animosity was no more pronounced in the different-party condition than in the other conditions. When benchmarked against the two "baseline" conditions that lacked partisan cues or inter-party comparison, we found no evidence that participants who played against out-partisan opponents exhibited more 
(A) Group Fund - Competitive Fund Contributions

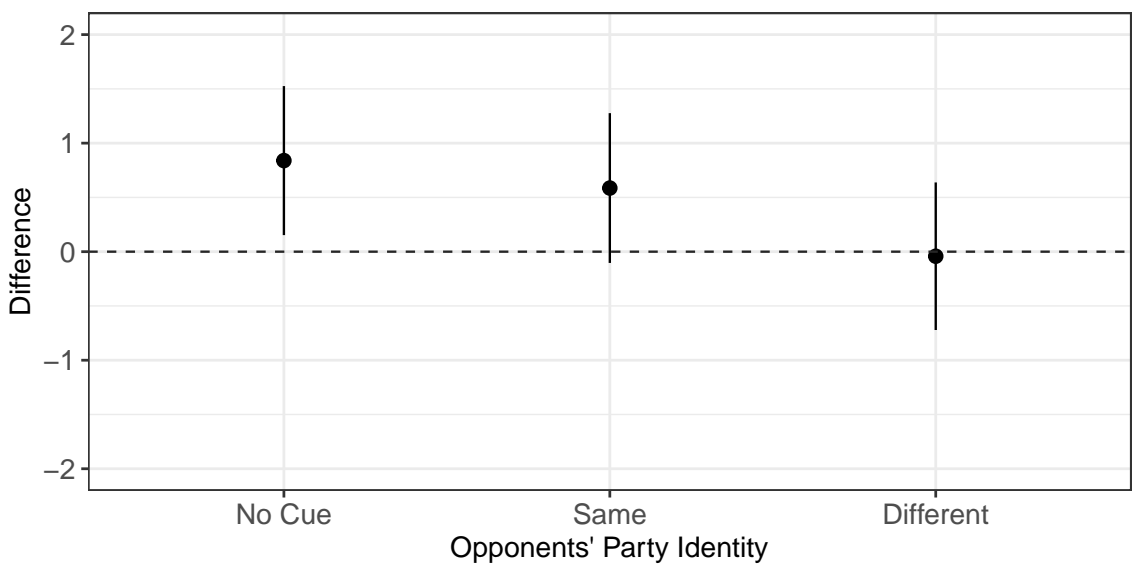

(B) Difference in the Group - Competitive Fund Contributions by Partisan Strength
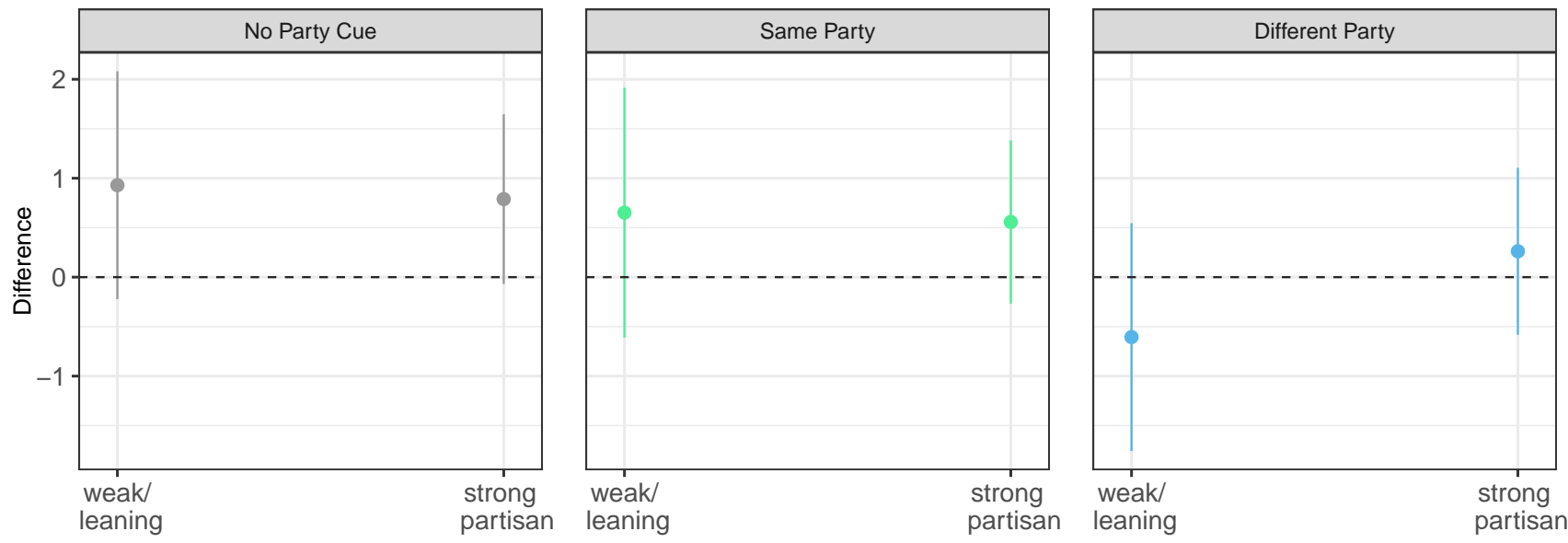

Note. The Figure depicts the difference in contributions to the Group Fund and Competitive Fund for each condition, with $95 \%$ confidence intervals. Values below zero indicate that participants contributed more to the Competitive Fund than the Group Fund, which suggests that negative out-group behavior (active out-group animosity) is more dominant than positive in-group behavior (in-group favoritism). Based on the results presented in Table B1 in Appendix B.

Figure 7. Experiment 1. In-group favoritism versus active out-group animosity

negative out-group behaviors. More specifically, the extent of passive out-group animosity was not significantly greater in the different-party condition when compared to the same-party $(b=-.04, S E=0.47, P=.93, B F=0.03)$ and no-party-cue conditions ( $b=-.16, S E=.47, P=.73, B F=0.03$; see Table B2 in Appendix B). That is, the presence of out-partisans did not increase contributions to the Exclusive Fund. In sum, we find little evidence that partisan motivations increased negative behavior of passive out-group harm, which allows us to conclude that partisan behavior is not uniquely more negative than other generic group behavior.

As shown in the bottom panel of Figure 8, we find heterogeneous treatment effects by partisan strength, primarily between the different-party and same-party conditions $(b=2.02, S E=1.01, P=.047, B F=0.23)$. More specifically, having out-partisans or co-partisans as opponents led strong and weak/leaning partisans to act differently. For instance, strong partisans in the same-party condition tended to show more generosity toward their opponents who were co-partisans by contributing to the Common Fund at a higher rate ( $M_{\text {Common-Exclusive }}=-0.29,95 \%$ CI $\left.[-1.09,0.52]\right)$ than did weak and leaning partisans $\left(M_{\text {Common-Exclusive }}=-1.52,95 \%\right.$ CI $\left.[-2.67,-0.38]\right)$, although the differences by partisan strength fell short of statistical significance $(b=-1.23, S E=0.71, P=0.08, B F=0.24)$. In the different-party condition, strong partisans reacted more negatively toward out-partisan opponents by contributing more to the Exclusive than the Common Fund $\left(M_{\text {Common-Exclusive }}=-0.90,95 \% \mathrm{CI}[-1.70,-0.11]\right)$; by contrast, weak and leaning partisans were largely indifferent 
to the two funds $\left(M_{\text {Common-Exclusive }}=-0.11,95 \%\right.$ CI $\left.[-1.29,1.05]\right)$. But even then, the extent of passive animosity toward out-partisan opponents was not significantly greater for strong partisans than for weak/leaning partisans $(b=.79, S E=.79$, $P=.28, B F=0.10)$. In other words, the behavior of strong partisans in the context of partisan competition involved a passive form of negative out-party behavior but it was still not a dominant force.

(A) Common Fund - Exclusive Fund Contributions

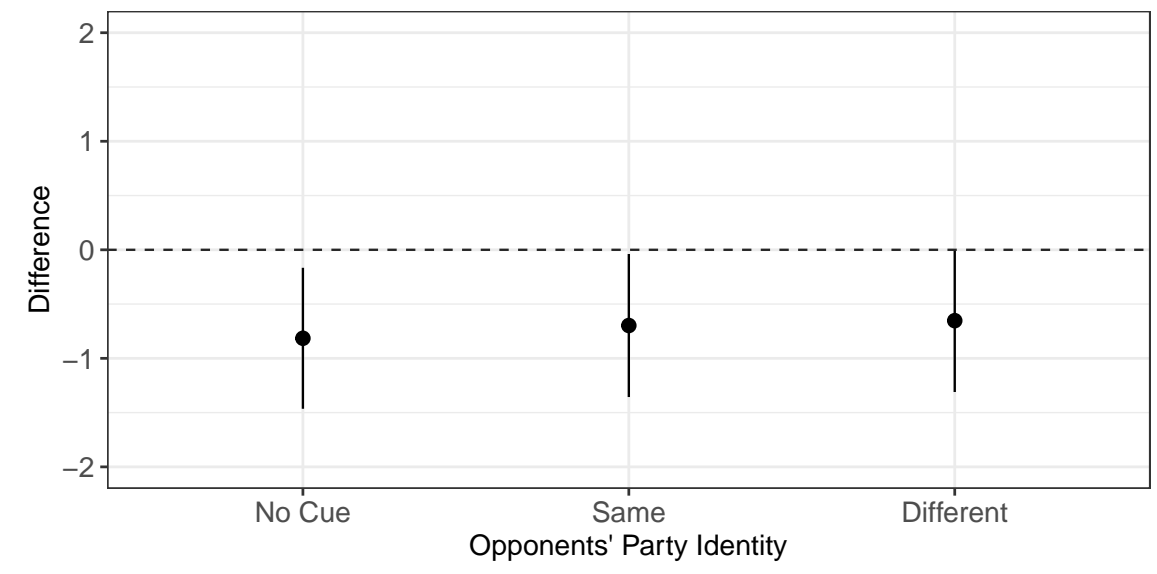

(B) Difference in the Common Fund - Exclusive Fund Contributions by Partisan Strength
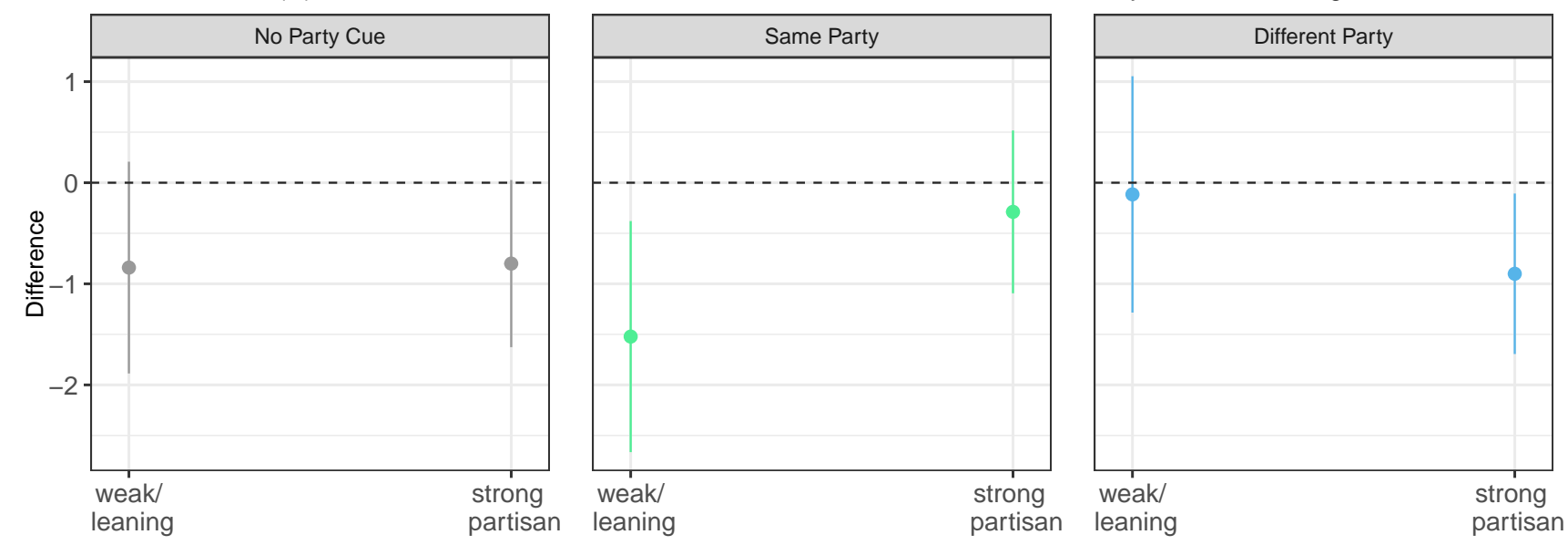

Note. The Figure depicts the difference in contributions to the Common Fund and Exclusive Fund for each condition, with 95\% confidence intervals. Values lower than zero indicate that participants contributed more to the Exclusive Fund than the Common Fund, which suggests negative out-group behavior (passive out-group animosity) being more dominant than positive in-group behavior (in-group favoritism). Based on the results presented in Table B2 in Appendix B.

Figure 8. Experiment 2. In-group favoritism versus passive out-group animosity

\section{Discussion and Conclusion}

Political reports in the recent years have painted a grim picture of American politics—-the country is hopelessly polarized, and people are growing angrier and more spiteful toward those on the other side, to the point that some rationalize or endorse actions that may actively harm their political opponents ${ }^{7}$. Negative partisanship, or hatred of the other party, has become a popular concept in explaining the current political landscape ${ }^{2 ; 6 ; 14 ; 44}$, yet our results demonstrate that such a perspective is vastly overstated (for similar arguments, see ref. ${ }^{45 ; 46}$ ). Using three distinct survey measures as well as two behavioral games, we have found no evidence that the overall charge of partisanship for Americans is predominantly negative. Our results are similar regardless of whether the measure focuses on political elites (in the feeling thermometer measures), groups and identities (in the negational identity measures), or individuals (in the behavioral game). 
To be clear, we cannot say that partisanship is primarily positive either. While the results using the negational-to-affirmational identity scale show that political identity tends to be based on positive/affirmational grounds for most people, our other measures based on feeling thermometer scores, the Bankert scales, and the behavioral games indicate that most partisans have both positive in-party attachments and negative out-party animosity and exhibit both positive in-group and negative out-group behaviors.

We also find that partisan identity is constructed on different grounds for party identifiers versus leaners. Strong and weak party identifiers, for which we find more support for positive than negative partisanship, appear to form their partisan identity based on positive considerations, i.e., what they like about their party, than they do based on negative considerations, i.e., what they dislike about the other party. On the other hand, it seems that leaners, who tend to be less interested and involved in politics, base their partisanship on their dislike of a particular political party. For them, negative considerations may provide an "easier" guide to navigate politics, as elections and political processes are increasingly framed as choosing the lesser of two evils 47 .

The disconnect between prior literature on negative partisanship and our findings may have to do with the measurement issue. A key component of the negative partisanship argument is that Americans' views of the other party have grown more negative and colder over time. However, our study shows that feeling thermometer ratings of the out-party are only weakly correlated with other direct measures of positive and negative partisan attachment. Even if people are showing more animosity toward the other side when measured with the feeling thermometer, that does not constitute strong evidence that their partisan identity is predicated on the out-party dislike ${ }^{48}$. In other words, feeling thermometers (or at least out-party feeling thermometers) may not be an adequate measure to assess positive/negative partisanship. Our data based on explicit measures of party attachment and identification as well as behavioral experiments consistently produce very little support for the predominance of negative partisanship. Instead, we find that Americans' partisan identity is a mix of positive and negative attitudes and sentiments.

While our findings temper the negative partisanship literature, they are also somewhat at odds with the social psychological literature that considers social identities to be primarily rooted in positive in-group attachment ${ }^{17 ; 37 ; 49}$. Past studies using the original IPD-MD experiments in the minimal group paradigm have shown that individuals are far more likely to contribute to help in-group players than hurt out-group players ${ }^{37 ; 39}$. In our experiments, however, participants engaged in both positive and negative behavior to a similar degree. This suggests that the nature of partisan attachment may be different from other social identities. Perhaps it is because politics tends to evoke strong emotions among its citizens and involves a substantial disagreement over moral issues, which can both contribute to the conditions to activate and energize out-group hate. Past literature has observed that in-group attachment can lead to out-group animosity when "out-groups are associated with stronger emotions" ${ }^{20}$. Additionally, out-group derogation can occur when identification is based on morality ${ }^{50}$ or because of the two-party political system in the United States ${ }^{51}$.

The strength of our argument lies in the use of multiple measures of the concept drawn from multiple data sources and the use of both survey and experimental methods. Besides the common feeling thermometer measure, we employed other survey measures that tap into partisan attachment more directly. Further, the behavioral games provided useful insight into how partisans behave in response to identity cues.

It should be noted that our experimental design attempted to approximate real-world conditions, in which people typically gather various pieces of information about others and not just their party identity. Had we only provided party cues, they might have dominated the participants' decision-making and we might have detected a stronger effect of partisanship. But instead, we provided party cues, along with non-political information about players, such as gender, age, and movie preferences. That way, our design corresponds to the real world and thus improves ecological validity. Further, even though the monetary incentives used in our study were small, numerous studies have demonstrated that the results of small-stakes behavioral experiments generally correlate with real-world behavior ${ }^{22 ; 52 ; 53 ; 54}$. Additionally, our experiments featured a one-shot game, but patterns of behavior observed in a single-shot IPD-MD game have been found to be consistent with behavior in a repeated game with multiple rounds, which mirrors the real world ${ }^{37 ; 39}$. All of these lines of evidence point to how our experimental findings could be generalized to real-life settings.

Our behavioral experiments document partisan behavior in a way that reduces social desirability bias relative to surveys. Arguably, it is unclear how social desirability bias may influence our survey results, since there is little to suggest that partisans may wish to hide the negative nature of their party identity when responding to surveys. In fact, such a social desirability bias dynamic would itself question the negative charge of partisanship; negative partisanship suggests that voters might prefer to present their partisan attachment as affiliation with the lesser of two evils (though (author?) ${ }^{55}$ shows that even lesser-of-twoevils arguments can emerge from positive partisan identity). Nevertheless, to minimize any concerns that individuals may either be not fully aware of, or not willing to state, a negative partisan identity, we have also conducted the implicit association test. Those data too, which are detailed in the online appendix, also show no evidence of partisan attachment being primarily negative for most partisans.

The goal of this study was primarily descriptive, since we focused on examining the distribution of positive and negative partisanship among the American electorate. That being said, we did not investigate the impact of negative or positive 
partisanship on behavior, largely because we believe that such analyses based on cross-sectional data are prone to errors. An unbiased comparison of negative versus positive partisanship would require, for instance, manipulation of one construct without affecting the other. This is certainly a worthwhile, albeit difficult, pursuit, which we leave for future study.

Our results have important implications for the current state of partisan polarization. While it is true that many Republicans and Democrats have grown polarized in their attitudes toward the parties, we find no evidence that negative partisanship and out-party hate dominate American politics. Our work suggests a more hopeful picture of the current political climate than suggested by some research and in the media. This is not to say that partisanship based on in-group affection is all benign. Passive animosity exhibited by strong partisans represents a less intentional and intense form of out-group negativity, but it can still have repercussions for out-group members ${ }^{18 ; 42}$.

Nevertheless, popular narratives emphasizing hatred of the other side create a vicious cycle that exacerbates affective polarization ${ }^{56 ; 57}$. When people believe that those in the other political camp despise them and are driven by prejudice and bias against them, inter-party relations will worsen ${ }^{57 ; 58}$. In a political system perceived to be dominated by partisan hatred, such perceptions make it more difficult to foster tolerance for other perspectives and support for compromise. What is more, political parties and candidates capitalizing on partisan anger and hatred may turn out to be a poor political strategy in the longer term. As most party identifiers are substantially driven by positive partisanship, the consistent use of negative rhetoric may be turning off those who are most likely to support them, a possibility supported by recent research ${ }^{23 ; 24 ; 59 ; 60}$. Our research demonstrates that politics is not, nor should it be, all negative.

\section{Methods}

\section{ANES Survey Data}

The American National Election Study (ANES) asks respondents to rate political parties and figures on a feeling thermometer ranging from 0 (very cold and unfavorable feeling) to 100 (very warm and favorable feeling), with 50 degrees as the neutral state of neither cold nor warm. We used the 1978-2020 ANES data on the feeling thermometer ratings of the Democratic and Republican parties. For Democratic and Republican identifiers, including leaners, we calculated the difference between in-party and out-party ratings for each of the available years. For the sake of consistency across years, we restrict the data to face-to-face interviews (and, in 2020, video interviews) because online responses tend to be more extreme and polarized than offline ones ${ }^{61}$.

To classify negative and positive partisan identity, we followed the procedure used in previous research $2 ; 12$ and defined voters as negative partisans if (97 - Out PartyRating) - In Party Rating $>0$, and positive partisans if (97-Out Party Rating) In PartyRating $<0$. We subtracted feeling thermometer scores from 97 rather 100, because the ANES CDF codes scored from 0 to 97. This specific form of the Feeling Thermometer began appearing in 1978. Although the ANES supplemented the face-to-face sample with an online sample, we restricted the sample to the face-to-face sample to make it comparable to past years.

\section{CCES Survey Data}

To assess the extent to which one's partisan identity is defined in affirmational (positive in-group identification) or negational (negative out-group disidentification) terms, we used an item adapted from prior research ${ }^{31}$ and fielded it in the 2016 Cooperative Congressional Election Study Survey $(n=1,611)$. Respondents were asked, "Sometimes we define our identities in terms of the groups we belong to and other times by the groups that we do not belong to. When it comes to political parties, would you say your party affiliation is based more on belonging to your own party or not belonging to the other party?" on a seven-point response scale: 1 (Strongly based on identifying with my own party), 2 (Moderately based on identifying with my own party), 3 (Slightly based on identifying with my own party), 4 (Equally based on identifying with my own party and not identifying with the other party), 5 (Slightly based on not identifying with the other party), 6 (Moderately based on not identifying with the other party), and 7 (Strongly based on not identifying with the other party).

We classified those who said their party identity was more based on disidentification with the other party as negative partisans. Those whose party identity was based more on identification with their own party were classified as positive partisans.

\section{SSI Survey Data}

We reanalyzed data collected by Bankert ${ }^{14}$. The sample consists of 887 partisans (including leaners) who were part of the Survey Sampling International (SSI). The survey was fielded in early November 2016. Respondents first reported their partisan identity. They then completed eight positive partisan identity questions, e.g., "When I talk about this party, I say 'we' instead of "them"” and eight negative partisan identity questions, e.g., "When I talk about this party, I say "we' instead of "them." See Appendix D for complete question wording. 


\section{IPD-MD Game}

We recruited our samples from an online research panel maintained by Bovitz Inc.'s Forthright. Following past work, we only recruited people who identified with or leaned toward the Republican Party or the Democratic Party. We oversampled Republicans to have an approximately equal number of Republicans and Democrats in the sample. See Appendix C for sample characteristics.

Participants were randomly assigned to take part in Experiment 1 or Experiment 2 . They first filled out a questionnaire asking about their demographics and party affiliation. We used this information to create player profiles that were shown to the participants during the game. We also asked about their favorite movie genre and included that information on the profiles to reduce the effects of demand characteristics. We did not mention anything about this study or game being about politics so as not to prime partisanship. Party affiliation was just one of several pieces of information asked and presented in the study.

Participants then read the game instructions and completed a practice session, where they were given a series of different possible scenarios and asked to calculate the payoffs. Most participants $(82.1 \%)$ correctly answered three or more times during the four rounds of practice. Limiting the analysis to these people who had a good understanding of the game does not change our results.

The IPD-MD game was played between two groups of three players each. All our participants were assigned the role of Player 1 of Team A, and they played the game with computer "confederates" who posed as other real participants.

After team assignment, participants were shown the profiles of all six players in the game that included their age, gender, party affiliation, and motive preferences. The profiles were created based on the participant's information and the treatment conditions. An example of the profiles presented is shown in Appendix B.

The key attribute we experimentally manipulated was partisanship. In all cases, the partisanship of players was kept the same within each group, and the participant's teammates always shared the same partisanship. Between the groups, however, partisanship varied depending on the conditions.

More specifically, participants were randomly assigned to play against an opposing team whose members had the same partisanship as the participant (Same Party condition), the opposite partisanship from the participant (Different Party condition), or with no information about anyone's partisanship (No Party Cue condition). A manipulation check confirms that perceptions of partisan similarity or dissimilarity between the groups were successfully manipulated $\left(\chi^{2}(8)=565.95, P<.001\right.$, see Appendix B). While manipulation was generally successful, there were only slight differences in perceived partisan similarity between the no-party cue and different-party conditions. However, this is not surprising as, by definition, no party cue was provided, and people would likely infer that people in other groups were less similar unless explicitly told about similarities.

Other pieces of information were randomly generated so that their effects are balanced out and do not affect the results; we randomly varied other players' ages within \pm 5 of the participant's age and also varied their gender to make the groups comparable in terms of gender composition. We also randomized others' movie preferences.

After viewing the player profiles (See Appendix B), participants were asked to decide how to divide their tokens between themselves and the group pools. There were two groups pools that served different functions in each experiment, which were key to achieving our primary objective: to distinguish between positive in-group behavior (in-group favoritism) or negative out-group behavior (out-group animosity). We informed our participants that all players have the same set of choices with the same payoff function. Participants played two rounds of the game with the same players, and everyone received 10 tokens (worth $\$ 0.10$ each) for each round. To incentivize participants, we told them that their payoffs would be determined by their own choice and the choices of other players, and that their final payoffs would be shown at the end of the game.

Experiment 1 The aim of Experiment 1 was to differentiate between in-group favoritism and active out-group animosity. 599 U.S. adults participated in Experiment 1. Our sample size was determined based on a power analysis where we assumed a small effect size $(f=.20)$ and a power of .90 . After being randomly assigned to one of three conditions (different-party, same-party, or no-party-cue) and shown the profiles of players, participants indicated how many tokens they want to keep, how many to contribute to the Group Fund, and how many to contribute to the Competitive Fund.

Each token kept by a player increased his or her payoff by two units without any impact on any other player's payoffs. The player's action affected others' payoffs only when the player made contributions to one of the funds. The main difference between the two funds is that the Group Fund only benefits a contributor's teammates, whereas the Competitive Fund benefits teammates while hurting opponents. When the player contributed to the Group Fund, each token increased the payoffs of all those in the same group, including the player, by one unit, but it had no impact on the payoffs of the players in the opposing group. By contrast, for each token contributed to the Competitive Fund, the player and his or her teammates earned profit but those in the opposing group lost profit; contributions to the Competitive Fund increased the payoffs of all those in the same group by one unit but decreased opponents' payoffs by one unit each.

Overall, participants contributed more of their endowment to their group (67\% of the endowment) than the amount they kept for themselves (33\%). Across two rounds of the game, the average number of tokens given to the Group Fund was $3.56(S E=0.12)$, and the average contribution to the Competitive Fund was 3.10 tokens $(S E=0.12)$. However, the pattern 
of contributions differed across conditions, depending on the partisanship of opponent players. See Appendix B for mean contributions by condition.

Experiment 2 In Experiment 2, we focused on differentiating between in-group favoritism and passive out-group animosity. Based on the same power analysis as in Experiment 1, we recruited 622 U.S. adults to participate in Experiment 2. Participants were randomly assigned to one of three party conditions, and asked to indicate how they wanted to allocate their tokens.

Keeping tokens had the same payoff function as in Experiment 1: for every token kept, the player gained two units, and it had no impact on others. The player's action had an impact on others' payoffs whenever the player contributed to either the Common Fund or the Exclusive Fund. The Exclusive Fund operates the same way as the Group Fund in Experiment 1, in that every token contributed by the player to the Exclusive Fund resulted in the payoffs of the player and his/her teammates being increased by one unit each, but it had no effect on the payoffs of those in the opposing group. In other words, the Exclusive Fund only benefited a player's teammates. On the other hand, the Common Fund benefited both teammates and opponents; when the player contributed to the Common Fund, everyone earned one unit for every token contributed, regardless of which group they belonged to.

Similar to Experiment 1, participants generally contributed more of their endowment (68\%) rather than keeping it for themselves $(32 \%)$. On average, participants contributed 3.75 tokens $(S E=0.11)$ to the Exclusive Fund and 3.03 tokens $(S E=0.11)$ to the Common Fund. See Appendix B for mean contributions by condition.

\section{Data Availability}

Data and code will be posted publicly upon publication.

\section{References}

\section{References}

1. Abramowitz, A. I. \& Webster, S. W. 'negative partisanship' explains everything. Politico. September 5. https://www. politico.com/magazine/story/2017/09/05/negative-partisanship-explains-everything-215534/. (2017).

2. Abramowitz, A. I. \& Webster, S. W. The Rise of Negative Partisanship and the Nationalization of U.S. Elections in the 21st Century. Elect. Stud. 41, 12-22, DOI: 10.1016/j.electstud.2015.11.001 (2016).

3. Abramowitz, A. I. \& Webster, S. W. Negative Partisanship: Why Americans Dislike Parties But Behave Like Rabid Partisans. Polit. Psychol. 39, 119-135, DOI: 10.1111/pops.12479 (2018).

4. Cassese, E. C. Dehumanization of the opposition in political campaigns. Soc. Sci. Q. 101, 107-120 (2020).

5. Cassese, E. C. Partisan dehumanization in american politics. Polit. Behav. 43, 29-50 (2021).

6. Iyengar, S. \& Krupenkin, M. The strengthening of partisan affect. Polit. Psychol. 39, 201-218 (2018).

7. Kalmoe, N. \& Mason, L. Radical American Partisanship: Mapping Extreme Hostility, Its Causes, and the Consequences for Democracy (University of Chicago Press, Chicago, 2022).

8. Kalmoe, N. P., Gubler, J. R. \& Wood, D. A. Toward Conflict or Compromise? How Violent Metaphors Polarize Partisan Issue Attitudes. Polit. Commun. 0, 1-20, DOI: 10.1080/10584609.2017.1341965 (2017).

9. Nicholson, S. P. Polarizing cues. Am. J. Polit. Sci. 56, 52-66, DOI: 10.1111/j.1540-5907.2011.00541.x (2012).

10. Nicholson, S. P., Coe, C. M., Emory, J. \& Song, A. V. The politics of beauty: The effects of partisan bias on physical attractiveness. Polit. Behav. 38, 883-898 (2016).

11. Mason, L. Uncivil Agreement: How Politics Became Our Identity (University of Chicago Press, Chicago, 2018).

12. Webster, S. W. American Rage (Cambridge University Press, 2020).

13. Iyengar, S. \& Krupenkin, M. The strengthening of partisan affect. Polit. Psychol. 39, 201-218 (2018).

14. Bankert, A. Negative and Positive Partisanship in the 2016 U.S. Presidential Elections. Polit. Behav. DOI: 10.1007/ s11109-020-09599-1 (2020). 
15. Iyengar, S., Sood, G. \& Lelkes, Y. Affect, not ideology: A social identity perspective on polarization. Public Opin. Q. 76, 405-431 (2012).

16. Tajfel, H. \& Turner, J. C. An Integrative Theory of Intergroup Conflict. In Austin, W. G. \& Worchel, S. (eds.) The Social Psychology of Intergroup Relations (Wadsworth, 1979, Monterey, CA, 1979).

17. Brewer, M. B. The Psychology of Prejudice: Ingroup Love or Outgroup Hate? J. Soc. Issues 55, 429-444 (1999).

18. Greenwald, A. G. \& Pettigrew, T. F. With Malice toward None and Charity for Some: Ingroup Favoritism Enables Discrimination. Am. Psychol. 69, 669-684, DOI: 10.1037/a0036056 (2014).

19. Huber, G. A. \& Malhotra, N. Political homophily in social relationships: Evidence from online dating behavior. The $J$. Polit. 79, 269-283 (2017).

20. Hewstone, M., Rubin, M. \& Willis, H. Intergroup Bias. Annu. Rev. Psychol. 53, 575-604 (2002).

21. Lelkes, Y. \& Westwood, S. J. The Limits of Partisan Prejudice. J. Polit. 79, 485-501, DOI: 10.1086/688223 (2017).

22. McConnell, C., Margalit, Y., Malhotra, N. \& Levendusky, M. The Economic Consequences of Partisanship in a Polarized Era. Am. J. Polit. Sci. 62, 5-18, DOI: 10.1111/ajps.12330 (2018).

23. Costa, M. Ideology, not affect: What americans want from political representation. Am. J. Polit. Sci. 65, 342-358 (2021).

24. Druckman, J. N., Klar, S., Krupnikov, Y., Levendusky, M. \& Ryan, J. B. (mis-) estimating affective polarization. J. Polit. (2021).

25. Medeiros, M. \& Noël, A. The Forgotten Side of Partisanship: Negative Party Identification in Four Anglo-American Democracies. Comp. Polit. Stud. 47, 1022-1046, DOI: 10.1177/0010414013488560 (2014).

26. Tajfel, H. Social identity and intergroup behaviour. Inf. (International Soc. Sci. Counc. 13, 65-93 (1974).

27. Morgan, S. L. \& Winship, C. Counterfactuals and Causal Inference (Cambridge University Press, 2015).

28. West, E. A. \& Iyengar, S. Partisanship as a social identity: Implications for polarization. Polit. Behav. 1-32 (2020).

29. Lelkes, Y. What do we mean by negative partisanship? The Forum: A J. Appl. Res. Contemp. Polit. (2021).

30. Druckman, J. N. \& Levendusky, M. S. What do we measure when we measure affective polarization? Public Opin. Q. 83, 114-122 (2019).

31. Zhong, C.-B., Phillips, K. W., Leonardelli, G. J. \& Galinsky, A. D. Negational categorization and intergroup behavior. Pers. Soc. Psychol. Bull. 44, 1563-1566 (2008).

32. Greene, S. Understanding Party Identification: A Social Identity Approach. Polit. Psychol. 20, 393-403, DOI: 10.1111/ 0162-895X.00150 (1999).

33. Iyengar, S., Lelkes, Y., Levendusky, M. S., Malhotra, N. \& Westwood, S. J. The origins and consequences of affective polarization in the united states. Annu. Rev. Polit. Sci. 22, 129-146, DOI: 10.1146/annurev-polisci-051117-073034 (2019).

34. Carlin, R. E. \& Love, G. J. The Politics of Interpersonal Trust and Reciprocity: An Experimental Approach. Polit. Behav. 35, 43-63, DOI: 10.1007/s11109-011-9181-x (2013).

35. Iyengar, S. \& Westwood, S. J. Fear and Loathing across Party Lines: New Evidence on Group Polarization. Am. J. Polit. Sci. 59, 690-707, DOI: 10.1111/ajps.12152 (2015).

36. Westwood, S. J., Peterson, E. \& Lelkes, Y. Are There Still Limits on Partisan Prejudice? Public Opin. Q. 83, 584-597 (2019).

37. Halevy, N., Bornstein, G. \& Sagiv, L. "In-Group Love" and "Out-Group Hate" as Motives for Individual Participation in Intergroup Conflict: A New Game Paradigm. Psychol. Sci. 19, 405-411 (2008).

38. Weisel, O. \& Böhm, R. "Ingroup Love" and "Outgroup Hate" in Intergroup Conflict between Natural Groups. J. Exp. Soc. Psychol. 60, 110-120, DOI: 10.1016/j.jesp.2015.04.008 (2015). 
39. Halevy, N., Weisel, O. \& Bornstein, G. "In-Group Love" and "Out-Group Hate" in Repeated Interaction Between Groups. J. Behav. Decis. Mak. 25, 188-195, DOI: 10.1002/bdm.726 (2012).

40. Tappin, B. M. \& McKay, R. T. Moral polarization and out-party hostility in the us political context. J. Soc. Polit. Psychol. 7, 213-245 (2019).

41. Cikara, M., Botvinick, M. M. \& Fiske, S. T. Us versus them: Social identity shapes neural responses to intergroup competition and harm. Psychol. science 22, 306-313 (2011).

42. Cuddy, A. J. C., Fiske, S. T. \& Glick, P. The BIAS map: Behaviors from Intergroup Affect and Stereotypes. J. Pers. Soc. Psychol. 92, 631-648, DOI: 10.1037/0022-3514.92.4.631 (2007).

43. Rudman, L. A. \& Ashmore, R. D. Discrimination and the implicit association test. Group Process. \& Intergroup Relations 10, 359-372 (2007).

44. Finkel, E. J. et al. Political Sectarianism in America. Science 370, 533-536 (2020).

45. Klar, S. \& Krupnikov, Y. Independent in America: Why People Avoid Partisanship and Why It Matters. (Cambridge University Press, New York, NY, 2016).

46. Klar, S., Krupnikov, Y. \& Ryan, J. B. Affective Polarization or Partisan Disdain? Untangling a Dislike for the Opposing Party from a Dislike of Partisanship. Public Opin. Q. 82, 379-390 (2018).

47. Delkic, M. Voters choosing among 'lesser of two evils,' survey finds. ABC News. September 29. https://abcnews.go.com/ Politics/voters-choosing-lesser-evils-survey-finds/story?id=42460153 (2016).

48. Jordan, J. J. \& Rand, D. G. Signaling when no one is watching: A reputation heuristics account of outrage and punishment in one-shot anonymous interactions. J. personality social psychology 118, 57 (2020).

49. Mummendey, A. \& Wenzel, M. Social discrimination and tolerance in intergroup relations: Reactions to intergroup difference. Pers. Soc. Psychol. Rev. 3, 158-174 (1999).

50. Parker, M. T. \& Janoff-Bulman, R. Lessons from morality-based social identity: The power of outgroup "hate," not just ingroup "love”. Soc. Justice Res. 26, 81-96 (2013).

51. Gidron, N., Adams, J. \& Horne, W. American affective polarization in comparative perspective (Cambridge University Press, 2020).

52. Benz, M. \& Meier, S. Do People Behave in Experiments As in the Field? Exp. Econ. 11, 268-281, DOI: 10.1007/ s10683-007-9192-y (2008).

53. Galizzi, M. M. \& Navarro-Martínez, D. On the external validity of social preference games: A systematic lab-field study. Manag. Sci. 65, 976-1002 (2018).

54. Alm, J., Bloomquist, K. M. \& McKee, M. On the external validity of laboratory tax compliance experiments. Econ. Inq. 53, 1170-1186 (2015).

55. Groenendyk, E. Competing Motives in the Partisan Mind: How Loyalty and Responsiveness Shape Party Identification and Democracy (Oxford University Press, 2013).

56. Levendusky, M. \& Malhotra, N. Does Media Coverage of Partisan Polarization Affect Political Attitudes? Polit. Commun. 33, 283-301 (2016).

57. Lees, J. \& Cikara, M. Inaccurate group meta-perceptions drive negative out-group attributions in competitive contexts. Nat. Hum. Behav. 4, 279-286 (2020).

58. Moore-Berg, S. L., Ankori-Karlinsky, L.-O., Hameiri, B. \& Bruneau, E. Exaggerated meta-perceptions predict intergroup hostility between American political partisans. Proc. Natl. Acad. Sci. 117, 14864-14872, DOI: 10.1073/pnas.2001263117 (2020).

59. Groenendyk, E., Sances, M. W. \& Zhirkov, K. Intra party polarization in american politics. The J. Polit. 82, 1616-1620 (2020). 
60. Druckman, J. N., Gubitz, S., Lloyd, A. M. \& Levendusky, M. S. How incivility on partisan media (de) polarizes the electorate. The J. Polit. 81, 291-295 (2019).

61. Iyengar, S. \& Krupenkin, M. The strengthening of partisan affect. Polit. Psychol. 39, 201-218 (2018).

\section{Acknowledgements}

We wish to acknowledge Alexa Bankert, Henry Brady, Jamie Druckman, Pat Egan, Andrew Guess, Stephen Goggin, John Henderson, Kristin Lane, Matt Levendusky, Brian Nosek, Eric Schickler, Jas Sekhon, N. Sriram, and Rob Van Houweling and participants in the Racial Attitudes in a Time of Growing Partisan Polarization Workshop at Princeton University for feedback. This research funded by the University of California, Merced, the University of Pennsylvania, and the Vanderbilt University Center for the Study of Democratic Institutions, and was supported by National Science Foundation Awards \#1559125 and \#1756447. We also thank Project Implicit and the Vanderbilt Research on Individuals, Politics and Society Lab.

\section{Author Contributions}

A.H.L., Y.L., C.B.H. and A.G.T. designed the studies, conducted the analyses, and drafted and revised the manuscript.

\section{Competing Interests}

The authors declare no competing interests. 